\title{
Cerebrospinal fluid activity of tissue plasminogen activator in patients with neurological diseases
}

\author{
F O T Akenami, V Sirén, M Koskiniemi, M A Siimes, H Teräväinen, A Vaheri
}

\begin{abstract}
Aim-To study cerebrospinal fluid (CSF) activity of tissue plasminogen activator (tPA) in patients with neurological diseases.

Methods-CSF tPA and urokinase (uPA) activities were studied using an immunocapture assay and zymography in 44 patients with neurological disease and 20 reference subjects. The patient group comprised three patients with meningitis, 21 with encephalitis, nine with acute 1 ymphoblastic $(n=7)$ and myeloid $(n=2)$ leukaemia, seven with multiple sclerosis, three with facial paresis, and one with polyradiculitis.
\end{abstract}

Results-Raised tPA activities were observed in patients with multiple sclerosis, leukaemia and encephalitis. In contrast, there were no differences in the mean activities of tPA in patients with meningitis or other diseases compared with the reference subjects. The highest tPA activities were found in patients with multiple sclerosis. The mean activity in patients with leukaemia was higher than in those with meningitis and polyradiculitis, but not encephalitis and facial paresis. Although the CSF tPA activity correlated positively with age in reference subjects, no correlation was observed in patients. Samples were qualitatively screened for both tPA and uPA activity by zymography and positive samples were quantitated. Some of the samples had quantifiable levels of uPA activity: three of seven multiple sclerosis samples, 10 of 21 samples from patients with encephalitis and five of nine leukaemic samples. The highest activities were recorded in patients with leukaemia. uPA was not detected in the CSF of the patients with meningitis, facial paresis or polyradiculitis.

Conclusions-Plasminogen activator activity can be measured reliably in CSF and the assessment of tPA activity may be useful for studying the pathogenesis of neurological diseases.

( $F$ Clin Pathol 1996;49:577-580)

Keywords: cerebrospinal fluid, neurological diseases, plasminogen activators.

Plasminogen activators, tissue-type (tPA) and urokinase-type (uPA), are serine proteases, the most well characterised function of which is the conversion of the inactive zymogen plas- minogen into the active protease plasmin. Plasminogen activators have been implicated in a number of biological processes, including fibrinolysis and thrombolysis, cell migration, tissue invasion by both normal and malignant cells, and tissue remodelling. ${ }^{12}$ Altered plasminogen activation has been reported in patients with diabetes ${ }^{34}$ and rheumatoid arthritis. ${ }^{5}$ The latter study also recorded raised plasmin concentrations in synovial fluid. ${ }^{5}$ Similarly, high plasma plasminogen activator concentrations have been observed in patients with acute non-lymphoblastic leukaemia. ${ }^{6}$ Ridker et $a l^{l}$ reported that in prospectively collected blood samples, high concentrations of endogenous tPA, the primary mediator of intravascular fibrinolysis, in apparently healthy men are strongly associated with the risk of future myocardial infarction. Similarly, high concentrations of tPA antigen in apparently healthy men have been reported to be independently associated with a high risk of stroke. ${ }^{8}$ tPA antigen concentrations have also been found to correlate with the presence of carotid atherosclerosis. ${ }^{9}$ Lipoprotein (a) has been reported to exert an atherogenic effect by inhibiting plasminogen activation..$^{10-12}$ Moreover, the roles of plasminogen activators and plasminogen activation inhibitors (PAI-1 and PAI-2) in the pathogenesis of neurological diseases and tumour development have been reported. ${ }^{13-16}$ The tPA gene is expressed in the developing brain ${ }^{17-19}$ and in human tumour cells of neuroectodermal origin. ${ }^{20}$

Here, we report the activity of plasminogen activators in cerebrospinal fluid (CSF) of patients with multiple sclerosis, encephalitis, meningitis, polyradiculitis, facial paresis, and leukaemia in comparison with reference subjects without neurological disease.

\section{Methods}

STUDY POPULATION/CHOICE OF SAMPLES

The procedures followed were in accord with the Helsinki Declaration of 1975 as revised in 1983 for human experimentation. This preliminary study initially involved 200 subjects undergoing spinal taps for clinical reasons, from whom about $1 \mathrm{ml}$ of CSF was drawn into plain plastic containers. Samples were accepted for this study if the difference in time in days between specimen collection and analysis was less than or equal to 10 . The final diagnosis was confirmed by the clinician. Samples which had been kept frozen for more than 10 days were excluded. Selection of samples became necessary when we observed that the 
tPA activity correlated negatively with storage time. Samples from 64 subjects (from newborn to 77 years of age), with a storage time of less than 10 days, were included in this study. Subjects with no neurological disease $(n=20)$ served as controls. The patient group comprised three patients with meningitis, 21 with encephalitis, seven with multiple sclerosis, three with facial paresis, one with polyradiculitis, seven with acute lymphoblastic leukaemia, and two with acute myeloid leukaemia.

\section{ZYMOGRAPHY}

Zymography was used for the qualitative detection of plasminogen activator activity in CSF. Briefly, samples were run on an $8 \%$ polyacrylamide gel in the presence of SDS under non-reducing conditions. ${ }^{21}$ The molecular weights of the lysed bands were estimated by comparison with pre-stained low molecular weight marker proteins (Pharmacia, Uppsala, Sweden). Activity standards of uPA (Calbiochem, La Jolla, California, USA) and tPA (American Diagnostica, Greenwich, Connecticut, USA) were also included. Before zymography, SDS was removed by washing the gel for six hours with phosphate buffered saline (PBS), $\mathrm{pH} 7.4$, containing $2.5 \%$ Triton $\mathrm{X}-100$. An agarose gel containing casein and $1.7 \mu \mathrm{g} / \mathrm{ml}$ plasminogen was then placed over the polyacrylamide gel, and the overlay incubated for $24-48$ hours at $37^{\circ} \mathrm{C}$ in a humidified chamber. To characterise the protease present further, 10 $\mu \mathrm{g} / \mathrm{ml}$ of an anticatalytic monoclonal antibody directed against uPA (catalogue number 394; American Diagnostica) was added to the polyacrylamide gel before incubation with the casein-agarose gel.

IMMUNOCAPTURE ASSAY FOR TPA AND UPA

The UPA and TPA activities of CSF were measured by an immunocapture assay as reported previously. ${ }^{22}{ }^{23}$ Pro-uPA was activated by the addition of purified human plasminogen containing traces of plasmin. Thus, PAI- 1 and pro-uPA can be present together in the sample without interference. tPA was assayed by a slightly modified procedure using $20 \mu \mathrm{g} / \mathrm{ml}$ poly-D-lysine in the assay buffer. Briefly, polystyrene microplate wells (Nunc, Roskilde, Denmark) were coated overnight at $37^{\circ} \mathrm{C}$ with $50 \mu \mathrm{l}$ of a solution of rabbit or goat antihuman IgG antibodies directed against either human uPA $(10 \mu \mathrm{g} / \mathrm{ml})$ or tPA $(2.5 \mu \mathrm{g} / \mathrm{ml})$ (catalogue numbers 389 and 387, respectively; American Diagnostica). The plates were washed three times with PBS, $\mathrm{pH} 7.2$, containing $0.05 \%$ Tween 20. Fifty microlitres of CSF were then dispensed and allowed to bind for two hours at room temperature. After binding, the wells were washed again (three times with PBS/ Tween), and human plasminogen containing traces of plasmin was added to assay the proenzyme activity bound to the wells $(2 \mu \mathrm{g}$ in $50 \mu \mathrm{l}$ uPA assay buffer consisting of $50 \mathrm{mM}$ glycine $\mathrm{pH} 7.8,0.1 \%$ Triton $\mathrm{X}-100,0.1 \%$ gelatin, and $10 \mathrm{mM}$ 6-aminocaproic acid). Plasminogen was purified from fresh human plasma by affinity chromatography on lysineSepharose. ${ }^{24}$ The reaction with plasminogen
Table 1 Cerebrospinal fluid activities of plasminogen activators and their $p$ values in comparison with the reference subjects (mean (SEM))

\begin{tabular}{|c|c|c|}
\hline Subject group & $t P A(\mu I U / m l)$ & $u P A(\mu I U / m l)$ \\
\hline Reference subjects $(n=20)$ & $43.7(6)$ & 0 \\
\hline Multiple sclerosis $(n=7)$ & $497 \quad(23) \dagger$ & $14.0(2)$ \\
\hline Leukaemia $(n=9)$ & $275(48)^{\star \star \star}$ & $55.0(15)$ \\
\hline Encephalitis $(n=21)$ & $245 \quad(25) \dagger$ & $28.0(8)$ \\
\hline Meningitis $(n=3)$ & $63.5(25)$ & 0 \\
\hline Facial paresis $(n=3)$ & $199(0)$ & 0 \\
\hline Polyradiculitis $(n=1)$ & 51.7 & 0 \\
\hline
\end{tabular}

was allowed to proceed for 45 minutes at $37^{\circ} \mathrm{Co}$ and the plasmin produced was assayed by its thioesterase activity. ${ }^{25}$ To estimate the amoun $\mathbb{R}$ of enzyme produced, high molecular weighణ two-chain uPA (80 000 IU/mg; AmericanDiagnostica) and two-chain tPA (650000 IU/mg; American Diagnostica) were used as standards.

STATISTICS

Results are reported as mean (SEM). The Stu-iv dent's $t$ test was used for the comparison of means. Correlation coefficients were evaluated according to Pearson. Results were consideredP significant when $\mathrm{p} \leqslant 0.05$.

Results uPA and tPA activity by zymography and positive samples were quantitated by the immuno-o capture assay. Positive samples were seen as lytic bands of tPA at molecular weight of $70 \mathrm{Q}$ kilodaltons and uPA at molecular weight of $50^{\circ}$ kilodaltons (data not shown).

We observed significantly higher mean tPAO activities in patients with multiple sclerosis $(\mathrm{p}<0.0001)$, leukaemia $(\mathrm{p}<0.001)$ and en cephalitis $(\mathrm{p}<0.0001)$ in comparison with the reference subjects (table 1 ).

In contrast, there were no statistically signifi-욱 cant differences in the mean activities of tPA in patients with meningitis, facial paresis and? polyradiculitis when compared with the refer-ence subjects (table 1). The mean tPA activity in patients with multiple sclerosis was veryo increased compared with the mean activities in each of the other patient groups. The meano activity in patients with leukaemia was higher than the mean activities in those with meningi-N tis and polyradiculitis, but not in those witho encephalitis and facial paresis.

The CSF tPA activity correlated positively with age in the reference subjects $(r=0.52 ; \mathrm{p} \stackrel{?}{?}$ 0.018 ). No correlation was observed in pa-0 tients with leukaemia, encephalitis and multi음 ple sclerosis.

Some of the samples had quantifiable levels of UPA activity: three of seven samples from patients with multiple sclerosis, 10 of 21 from those with encephalitis and five of nine? from patients with leukaemia. The highesto activities were recorded in patients with leukaemia (table 1).

\section{Discussion}

tPA activity in patients with multiple sclerosis was raised consistently and was significantly higher than in any of the other groups studied. 
Multiple sclerosis is a chronic disease of the central nervous system of largely unknown aetiology, affecting young and middle aged adults. The myelin sheaths surrounding nerves in the brain and spinal cord are damaged, which affects the function of the nerves involved. The disease affects different parts of the brain and spinal cord, resulting in typically scattered symptoms. The involvement of plasminogen activator induction in the pathogenesis of multiple sclerosis and encephalitis has been suggested by studies of peripheral blood lymphocytes. ${ }^{26}$ The authors also reported the disappearance of plasminogen activator induction in association with resolution of neurological symptoms. ${ }^{26}$

It is also worth considering activation of the vascular endothelium, as this is thought to have an important role in the pathogenesis of inflammation, thrombosis and vasculitis. Endothelial activation plays a central role in the pathogenesis of multiple sclerosis and encephalitis. Furthermore, proteases and cytokines have also been implicated in these diseases. ${ }^{26-31}$ Activation of endothelial cells in patients with encephalitis by vasoactive amines and proteases induces vasospasm and breakdown of the blood-brain barrier. ${ }^{28}$ The damage to the blood-brain barrier leads to biochemical changes in the CSF as previously impermeable substances can pass through the barrier more freely. ${ }^{32}$ The damage to the blood-brain barrier perhaps explains the raised tPA activity observed in patients with encephalitis and normal activity in those with meningitis. The same mechanism of tissue destruction is thought to be active in autoimmune encephalomyelitis and multiple sclerosis. ${ }^{27}$

In contrast, the tPA activities observed in patients with meningitis, facial paresis and polyradiculitis were very similar to those observed in the reference subjects. The CSF tPA activity correlated positively with age in the reference subjects; no correlation was observed in any of the other groups. The tPA activity also correlated negatively with the interval between sample collection and analysis; samples were stable for up to 10 days when stored frozen. This was not the case for uPA, which may be the result of the very low levels of uPA activity detected in these samples.

The significance of tPA gene expression in the developing brain is not understood clearly. ${ }^{17-19}$ According to Carroll et al ${ }^{17}$ in the adult rat brain, transcription of the tPA gene is an immediate early response in the hippocampus following the induction of neuronal plasticity. The results they obtained supported the concept that tPA plays a role in neurogenesis and morphogenesis, and identified the promoter region that directs transcriptional regulation, both during development and in the adult central nervous system. tPA is the main plasminogen activator associated with the rat brain growth cones, suggesting that it is required for neurite growth ${ }^{18}$ tPA expression during embryogenesis has been confirmed by in situ hybridisation. ${ }^{19}$ The results indicate strongest expression in the basal midbrain and hindbrain, continuing posteriorly into the neu- ral canal. The expression coincides with extensive cell migration and proliferation, and tissue remodelling in these regions. It seems that tPA is expressed by a number of different cell types in the developing nervous system and may also play a role in cell migration and tissue remodelling in later life.

Some of the samples had quantifiable levels of uPA activity. The highest uPA activity was recorded in samples from patients with leukaemia. Myeloid leukemia cells have been found to produce either tPA or UPA in culture. ${ }^{33}$ Cell surface bound UPA activity has been detected in patients with acute leukaemia, whereas plasminogen activator activity was not detected in mononuclear cells from either healthy controls or patients with chronic lymphoid leukaemia. ${ }^{34}$

Zymography was more suitable for the detection of uPA than tPA. The latter could only be detected when a thinner casein-milk gel was used as the overlay. The uPA activities detected in the present study were so low that the immunocapture assay was probably not the most appropriate quantitative assay. Some samples which had detectable uPA activity on zymography, had no measurable activity in the immunocapture assay. Such results can occur if the uPA is non-covalently bound either to an inhibitor or to another protein inhibiting the binding of this serine protease to the immunocapture plate.

Samples from patients with leukaemia had high tPA activities and most had quantifiable uPA activity. Earlier studies of patients with myeloid leukaemia have shown that cells from these patients produce either tPA or UPA in culture. The type of plasminogen activator produced was found to have prognostic significance: patients whose cells secreted tPA failed to respond to chemotherapy, whereas $80 \%$ of those whose cells secreted uPA achieved remission. ${ }^{33}$ Wilson et a ${ }^{36}$ again reported that at the earlier stages of differentiation, the precursors of myeloid cells mainly produced tPA.

Further studies involving CSF are required to elucidate the role of plasminogen activators in the diagnosis and pathogenesis of the above clinical conditions, especially in multiple sclerosis, leukaemia and encephalitis, and possibly also in facial paresis. There will also be the need to study PAI-1 in the CSF of these patients, in comparison with concentrations present in CSF of normal subjects. ${ }^{37}$

The authors thank Ms Merja Lindfors for technical assistance and Dr Hannele Tapiovaara for useful discussion.

This work was supported by funds from the Nigerian National Universities Commission World Bank Assisted Staff Development programme, 1994, and the Medical Research Council of the Academy of Finland.

1 Danø K, Andreasen PA, Grøndahl-Hansen J, Kristensen K, Nielsen L, Skriver L. Plasminogen activators, tissue degradation and cancer. Adv Cancer Res 1985;44:139-266.

2 Pöllänen J, Stephens RW, Vaheri A. Directed plasminogen activation at the surface of normal and malignant cells. Adv Cancer Res 1991;57:273-328.

3 Almer L-O, Sundkvist G, Lilja B. Fibrinolytic activity, autonomic neuropathy, and circulation in diabetes mellitus. nomic neuropathy, and circula
Diabetes 1983;32(Suppl 2):4-7.

4 Geiger M, Binder BR. Plasminogen activation in diabetes mellitus. Kinetic analysis of plasmin formation using components isolated from the plasm
Biol Chem 1984;259:2976-81.

5 Inman RD, Harpel PC. Alpha 2-plasmin inhibitor-plasmin complexes in synovial fluid. $\mathcal{f}$ Rheumatol 1986;13:535-7. 
6 Garcia-Frade LJ, Sureda A, Torrado MC, Garcia-Avello A High plasma urokinase-type plasminogen activator levels are present in patients with acute nonlymphoblastic leukemia. Acta Haematol 1992;88:7-10.

7 Ridker PM, Vaughan DE, Stampfer MK, Manson JE, Hennekens $\mathrm{CH}$. Endogenous tissue-type plasminogen activator and risk of myocardial infarction. Lancet 1993, 341: 1 165-8.

8 Ridker PM, Hennekens CH, Stampfer MJ, Manson JE, Vaughan DE. Prospective study of endogenous tissue plasminogen activator and risk of stroke. Lancet 1994; minogen $940-3$.

9 Salomaa VV, Wu KK, Stinson VL, Kark JD, Folsom AR Liao $\mathrm{D}$, et al. The association of fibrinolytic activity with asymptomatic carotid atherosclerosis: the ARIC study. Circulation 1993;87:22.

10 Short CD, Durrington PN, Mallick NP, Bhatnagar D, Hun NP, Mbewu A. Serum lipoprotein (a) in men with proteinuria due to idiopathic membranous nephropathy. Nephrol Dial Transplant 1992;7(Suppl 1):109-13.

11 Bartens W, Wanner C. Lipoprotein (a): new insights into an atherogenic lipoprotein. Clin Invest 1994;72:558-67.

12 Chapman MJ, Huby T, Nigon F, Thillet J. Lipoprotein (a) implication in atherothrombosis. Atherosclerosis 1994, 110 (Suppl):S69-75.

13 Gijtenbeek JM, Emeis JJ, Van der Sande JJ, Lulf RE. Different types of plasminogen activator activity in human brain tumours: relation with peritumoral oedema? Clin Neurol Neurosurg 1994;96:305-9.

14 Sawaya R, Rayford A, Kono S, Ang KK, Feng Y, Stephens $\mathrm{CL}$, et al. Plasminogen activator inhibitor-1 in the pathogenesis of delayed radiation damage in rat spinal pathogenesis of delayed radiation dam
cord in vivo. F Neurosurg 1994;81:381-7.

15 Sutton R, Keohane ME, Van der Berg SR, Gonias SL. Plasminogen activator inhibitor-1 in the cerebrospinal fluid as an index of neurological disease. Blood Coagul Fibrinolysis 1994;5:167-71.

16 De Vries TJ, Mooy CM, Van Balken MR, Luyten GP, Quax $\mathrm{PH}$, Verspaget HW, et al. Components of the plasminogen activation system in uveal melanoma-a clinicopathological study. F Pathol 1995;175:59-67.

17 Carroll PM, Tsirka SE, Richards WG, Frohman MA Strickland S. The mouse tissue plasminogen activator gene 5 ' flanking region directs appropriate expression in gene $5^{\prime}$ flanking region directs appropriate expression in development and a seizure-enhanced

18 Garcia-Rocha M, Avila J, Armas-Porte R. Tissue-type plasminogen activators (tPA) is the main plasminogen activator associated with isolated rat nerve growth cones. Neurosci Lett 1994;180: 123-6.

19 Friedman GC, Seeds NW. Tissue plasminogen activator expression in the embryonic nervous system. Brain Res Dev Brain Res 1994;81:41-9.

20 Bizik J, Stephens RW, Grofova M, Vaheri A. Binding of tissue-type plasminogen activator to human melanoma tissue-type plasminogen activator to
cells. $\mathcal{F}$ Cell Biochem 1993;51:326-35.

21 Laemmli UK. Cleavage of structural proteins during the assembly of the head of bacteriophage T4. Nature 1970;227:680-2.
22 Stephens R, Leung KC, Pöllänen J, Salonen EM, Vaheri A Microplate immunocapture assay for plasminogen activators and their specific inhibitors. F Immunol Methods 1987 105: $245-51$

23 Stephens R, Alitalo R, Tapiovaara H, Vaheri A. Production of an active urokinase by leukemia cells: A novel distinction from cell lines of active tumors. Leuk Res 1988; 12:419-22.

24 Deutch DG, Mertz ET. Plasminogen: Purification from human plasma by affinity chromatography. Science 1970; 170:1095-7.

25 Green GDG, Shaw E. Thiobenzyloxycarbonyl-L-lysinate, substrate for a sensitive colorimetric assay for trypsin-like enzymes. Anal Biochem 1979;93:223-6.

26 Sugita K, Suzuki N, Shimizu N, Takanashi J, Ishii M, Niimi $\mathrm{N}$. Involvement of cytokines in $\mathrm{N}$-methyl-N'-nitro-Nnitrosoguanidine-induced plasminogen activator activity in acute disseminated encephalomyelitis and multiple sclerosis lymphocytes. Eur Neurol 1993;33:358-62.

27 Norton WT, Brosnan CF, Cammer W, Goldmuntz EA. Mechanisms and suppression of inflammatory demyelination. Acta Neurobiol Exp (Warsz) 1990;50:225-35.

28 Dore-Duffy P, Donovan C, Todd RF 3rd. Expression of monocyte activation antigen Mo3 on the surface of peripheral blood monocytes from patients with multiple sclerosis. Neurology 1992;42:1609-14.

29 Dore-Duffy P, Washington R, Dragovic L. Expression of endothelial cell activation antigens in microvessels from patients with multiple sclerosis. Adv Exp Med Biol 1993;331:243-8.

30 Washington R, Burton J, Todd RF 3rd, Newman W, 용 Dragovic L, Dore-Duffy P. The expression of immunologically relevant endothelial cell activation antigens on isolated central nervous system microvessels from patients isolated central nervous system microvessels from pati

31 Romanic AM, Madri JA. The extracellular matrixdegrading proteinases in the nervous system. Brain Pathol 1994;4:145-56.

32 Koskiniemi M, Vaheri A, Taskinen E. Cerebrospinal fluid alterations in herpes simplex virus encephalitis. Rev Infect Dis 1984;6:608-17.

33 Wilson EL, Jacobs P, Dowdle EB. The secretion of plasminogen activators by human myeloid leukaemic cells in vitro. Blood 1993;61:568-72.

34 Tapiovaara $\mathrm{H}$, Alitalo R, Stephens R, Myöhänen $\mathrm{H}$, Ruutu $\mathrm{T}$, Vaheri A Abundant urokinase activity on the surface of mononuclear cells from blood and bone marrow of acute leukemia patients. Blood 1993;82:914-19.

35 Stephens RW, Tapiovaara H, Reisberg T, Bizik J, Vaheri A. Alpha-2-macroglobulin restricts plasminogen activation to the surface of RC2A leukemia cells. Cell Regul 1991; 2:1057-65.

36 Wilson EL, Jacobs P, Francis GE, Oliver L, Burger P, Dowdle EB. Secretion of plasminogen activators by normal bone marrow cells and leukaemic myeloid cells. Fibrinolysis 1992;6(Suppl 1):77.

37 Rao JS, Chen M, Festoff BW. Plasminogen activator inhibitor 1 , the primary regulator of fibrinolysis, in the normal human cerebrospinal fluid. 7 Neurosi Res 1993;34:340-5. 